DOI: https://doi.org/10.24127/ajpm.v10i3.3898

\title{
LITERASI DIGITAL SISWA DALAM PEMBELAJARAN MATEMATIKA BERBANTUAN MEDIA SPACE GEOMETRY FLIPBOOK (SGF)
}

\author{
Siti Nur Hasanah", Yus Mochammad Cholily ${ }^{2 *}$, Moh. Mahfud Effendi ${ }^{3}$, \\ Octavina Rizky Utami Putri ${ }^{4}$ \\ ${ }^{1,2 * 3,4}$ Universitas Muhammadiyah Malang, Malang, Indonesia \\ ${ }^{*}$ Corresponding author. Jl Raya Tlogomas No 246, 65144, Malang, Indonesia. \\ E-mail: $\quad$ hazanah@webmail.umm.ac.id ${ }^{1)}$ \\ yus@umm.ac.id ${ }^{2 *}$ \\ mahfud@umm.ac.id ${ }^{3)}$ \\ octavina@umm.ac.id ${ }^{4)}$
}

Received 01 July 2021; Received in revised form 13 September 2021; Accepted 15 September 2021

\begin{abstract}
Abstrak
Tujuan penelitian ini yaitu menganalisis literasi digital siswa dalam pembelajaran matematika yang berbantu media Space Geometry Flipbook (SGF). Untuk memperoleh data tentang literasi digital siswa menggunakan angket, lembar observasi serta wawancara secara mendalam. Angket di berikan kepada 3 siswa kelas IX SMP yang telah mengoperasikan media SGF. Untuk keabsahan data dilakukan wawancara secara mendalam terhadap siswa. Data dianalisis dengan mereduksi data pada tabel angket, lembar observasi serta wawancara. Kemudian menyajikannya dalam bentuk naratif, dan menarik kesimpulan. Hasil penelitian ini menunjukkan bahwa literasi digital siswa dalam pembelajaran matematika dengan berbantuan media SGF masuk kategori tinggi. Oleh karena itu pembelajaran matematika berbantuan media SGF perlu dikembangkan dan diterapkan agar literasi digital siswa meningkat.
\end{abstract}

Kata kunci: Literasi digital; pembelajaran matematika; space geometry flipbook.

\begin{abstract}
The purpose of this study is to analyze students' digital literacy in learning mathematics with the help of the Space Geometry Flipbook (SGF) media. To obtain data about digital literacy students use questionnaires, observation sheets and in-depth interviews. Questionnaires were given to 3 grade IX junior high school students who have operated SGF media. For the validity of the data, in-depth interviews were conducted with students. Data were analyzed by reducing the data in the questionnaire table, observation sheets and interviews. Then present it in narrative form, and draw conclusions. The results of this study indicate that the digital literacy of students in mathematics learning assisted by SGF media is in the high category. Therefore, SGF media-assisted mathematics learning needs to be developed and applied so that students' digital literacy increases.
\end{abstract}

Keywords : Literasi digital; pembelajaran matematika; space geometry flipbook.

This is an open access article under the Creative Commons Attribution 4.0 International License

\section{PENDAHULUAN}

Di era revolusi digital, perkembangan teknologi dan informasi berkembang semakin pesat seiring dengan meningkatnya kebutuan manusia (Reflianto \& Syamsuar, 2018). Teknlogi informasi memegang peranan penting dalam keseharian manusia, termasuk dalam bidang pendidikan. Pendidikan matematika di Indonesia berkembang seiring dengan berkembangnya teknologi informasi yang semakin canggih. Kehadiran teknologi informasi telah membawa banyak perubahan seperti yang ditunjukan pada gaya hidup abad 21 yang terus berubah (Fernandes, 
2019). Kehidupan manusia saat ini tidak lengkap jika tidak menggunakan media digital, kebutuhan media digital sudah menjadi kebutuhan utama. Media digital telah memenuhi kehidupan sehari-hari manusia yang tanpa disadari keberadaannya serta pengaruhnya (Indariani, Ayni, Pramuditya, \& Noto, 2019; Kurniawati \& Baroroh, 2016). Media digital memudahkan masyarakat dalam membangun korelasi dengan orang lain dalam persoalan duniawi (Utami, 2020).

Kemampuan seseorang untuk menggunakan teknologi digital dalam memperoleh informasi dan menggunakan alat komunikasi untuk berinteraksi secara efektif disebut literasi digital (Casey \& Hallissy, 2016). Kemampuan Literasi digital merupakan keterampilan abad-21 yang dibutuhkan oleh siswa, antara lain sikap belajar, keterampilan sosial, keterampilan teknis dan kognitif (Rahayu \& Mayasari, 2018). Literasi digital merupakan salah satu bentuk pemikiran dalam masyarakat digital (Uswatun Khasanah \& Herina, 2019). Masyarakat digital mengacu pada orang-orang yang hidup dengan memanfaatkan teknologi digital serta gaya belajarnya mereka berbeda dari sebelumnya (Rahayu \& Mayasari, 2018). Saat ini sekolah mengahadapi tantangan untuk menanamkan literasi digital dalam kegiatan belajar mengajar (KBM) (Rahmawaty \& Karwanto, 2021). Penggunaan media digital saat pembelajaran dalam rangka meningkatkan efisiensi pembelajaran dikelas dengan harapan hasil belajar siswa meningkat karena media digital dapat menyajikan materi pelajaran dengan menarik dan interaktif (Anggraeni, Fauziyah, \& Fahyuni, 2019).

Media digital saat ini sedang menjadi mode baru dalam pembelajaran matematika. Belajar matematika merupakan sebuah proses untuk melatih otak agar berpikir logis dan sistematis (Lestari, Sunardi, \& Suryani, 2017). Namun, seringkali matematika dianggap pelajaran yang membosankan sehingga siswa sukar dalam memahami materi yang dijelaskan oleh guru. Kesulitan yang dialami siswa tersebut dapat diatasi dengan penggunaa media pembelajaran berbasis IT atau media digital, yang dikembangkan dengan menggunakan Flipbook Maker Pro (Andini, Fitriana, \& Budiyono, 2018). Software tersebut dapat mengubah bentuk pdf menjadi layaknya sebuah buku. Media yang dimaksud adalah $e$ book atau flipbook yang memuat audio, gambar, animasi, serta video didalamnya (Hasanah, Effendi, \& Putri, 2020). Penggunaan media flipbook dalam pembelajaran dapat menarik perhatian siswa serta meningkatkan keterampilan berfikir kreatif siswa (Selvia, Suratman, \& Hartoyo, 2016). Media flipbook juga membantu proses pembelajaran agar ketika membaca ebook tidak lagi monoton (Haryanti \& Saputro, 2016).

Penggunaan media pembelajaran flipbook dapat digunakan secara mandiri maupun klasikal dalam kelas. Pada penelitian ini, menggunakan media Space Geometry Flipbook (SGF) yang didalamnya memuat materi geometri. Kelebihan media Space Geometry Flipbbok (SGF) adalah sebagai alat bantu guru dalam menjelaskan konsep geometri seperti tabung, kerucut dan bola. Selain itu, siswa juga dapat menggunakanya untuk belajar mandiri dirumah. Kelebihan media SGF yaitu dikemas dengan tampilan kreatif, inovatif, serta interaktif sehingga motivasi belajar siswa meningkat dan mempengaruhi hasil belajaranya (Hardiansyah, 2016). Hal ini sejalan dengan penelitian Rusli \& Antonius (2019) yang menyatakan bahwa penggunaan media flipbook dapat 
meningkatkan minat belajar serta hasil belajar siswa. Penelitian lain juga menyatakan bahwa penggunaan media berbasis literasi digital saat pembelajaran bermanfaat bagi siswa (Raihanah, Putri, \& Effendi, 2020). Akan tetapi, Merujuk pada hasil PISA tahun 2015 menyatakan bahwa tingkat Literasi Indonesia berada di peringkat 62 dari 70 negara yang berarti tingkat literasi Indonesia masih rendah dan berada di bawah rata-rata (OECD, 2015). Literasi bukan hanya sekedar membaca, melainkan juga mengerti makna dalam bacaan tersebut. Dalam hal ini, literasi digital juga meliputi penguasaan ide/gagasan (A'yuni, 2015). Oleh karena itu, penelitian ini bertujuan untuk menganalisis literasi digital siswa dalam pembelajaran matematika yang memanfaatkan media SGF.

\section{METODE PENELITIAN}

Jenis Penelitian ini adalah penelitian deskriptif dan pendekatan penelitian ini adalah pendekatan kualitatif. Partisipan pada penelitian ini adalah 3 siswa kelas IX, S1 dengan berkemampuan tinggi, S2 dengan dengan kemampuan sedang, dan S3 siswa berkemampuan rendah . Berikut adalah tahapan yang dilakukan pada penelitian ini : (1) Penyusunan istrumen dan validasi instrumen, (2) Pemilihan subjek berdasarkan kemampuan tinggi, sedang, rendah , (3) Mengarahkan kepada siswa bagaimana menggunakan media, (4) Menginstruksikan siswa menggunakan media untuk belajar materi bangun ruang sisi lengkung, (5) Memberikan angket sebagai respon siswa terhadap media, dan menganalisisnya, (6) Mengamati siswa saat menggunakan media untuk mengetahui literasi digital siswa, dan menganalisisnya, (7) Menulis laporan penelitian.
Media SGF memuat materi bangun ruang sisi lengkung kelas IX SMP yang meliputi tabung, kerucut, dan bola. Media SGF memuat beberapa bagian, antara lain cara penggunaan media, video ilustrasi, deskripsi materi, video penjelaskan rumus bangun ruang sisi lengkung serta contoh soal. Instrumen penelitian ini adalah angket, lembar observasi, dan wawancara. Kemampuan memahami dan menggunakan media digital diukur menggunakan angket dengan penggunaan media SGF dengan kreativitas, efektivitas, efisiensi, serta ketertarikan siswa terhadap media. Kemudian pengamatan secara langsung dilakukan ketika siswa menggunakan media SGF dan dilanjutkan dengan wawancara secara mendalam setelah siswa menggunakan media SGF. Hal ini dilakuan untuk mengetahui tingkat literasi digital siswa, yang meliputi 4 indikator antara lain sikap belajar, sosial-emosional, teknis, serta kognitif. Analisis data dengan mereduksi data pada tabel angket, lembar observasi serta wawancara. Reduksi dilakukan dengan merangkum dan memilih hal-hal penting, kemudian menyajikanya dalam bentuk naratif, dan menarik kesimpulan. Validitas data penelitian melalui tringulasi yang merupakan penggabungan antara teknik observasi dan wawancara.

Analisis tingkat kemampuan literasi digital $(x)$ dikategorikan menjadi lima yaitu sangat rendah (SR), rendah $(\mathrm{R})$, sedang (S), tinggi $(\mathrm{T})$, dan sangat tinggi (ST) dengan interval berturutturut adalah : $0 \leq x \leq 54 ; 55 \leq x<$ 60; $60 \leq x<76 ; 76 \leq x<86 ; 86 \leq$ $x \leq 100$ (Sari \& Nada, 2020)

\section{HASIL DAN PEMBAHASAN}

Di era revolusi digital ini, siswa diharapkan mampu meningkatkan 
DOI: https://doi.org/10.24127/ajpm.v10i3.3898

kemampuan literasi digitalnya. Kemampuan siswa memahami dan mengoperasikan media digital diperoleh dari hasil angket respon siswa, yang meliputi kreativitas, keefektifan, efisiensi, dan ketertarikan siswa menggunakan media yang di uraikan sebagai berikut: Kreativitas media SGF antara lain (1) Media dapat menumbuhkan rasa ingin tahu siswa (2) media SGF menyediakan gambar yang sesuai materi (3) Media SGF membantu siswa dalam proses pembelajaran. Keefektifan media SGF antara lain, (1) Media dapat menyajikan semua komponen materi pelajaran dengan jelas (2) Media SGF merangsang keingintahuan siswa (3) Media SGF dilengkapi dengan contohcontoh soal (4) Materi dalam media SGF berkaitan dengan materi yang telah dipelajari sebelumnya (5) media SGF menyajikan Informasi secara lengkap dan jelas (6) Media SGF menghubungkan materi dengan perkembangan teknologi yang ada saat ini. Efisiensi media SGF tersebut antara lain (1) Media SGF mampu meningkatkan kualitas belajar siswa (2) Media SGF dapat membantu siswa menguasai materi pelajaran dengan cepat. Ketertarikan siswa terhadap media meliputi, (1) teks dan warna tulisan pada media jelas (2) gambar dan video yang menunjang materi pembelajaran
(3) suara yang terdengar jelas (4) Sajian materi berkaitan dengan kehidupan sehari-hari.

Tanggapan positif siswa diperoleh dari hasil angket respon siswa berdasarkan aspek kreativitas, efektivitas, efisiensi, dan ketertarikan siswa menggunakan media masuk kategori sangat baik. Penelitian ini sejalan dengan Willy Arif Indhaka, Eko Supraptono (2016) yang menyatakan bahwa siswa menunjukkan respon positif terhadap e-book karena dapat menimbulkan ketertarikan, perhatian lebih terfokus pada pembelajaran serta meningkatkan keterlibatan terhadap kegiatan belajar mengajar.

Tingkat literasi digital siswa juga diperoleh dari hasil pengamatan langsung terhadap siswa saat menggunakan media SGF. Terdapat 5 kategori penggolongan tingkat literasi digital siswa yaitu Sangat Tinggi (ST), Tinggi (T), Sedang (S), Rendah (R), Sangat Rendah (SR). Berdasarkan penelitian yang telah dilakukan, diperoleh persentase tingkat literasi digital siswa dari masing-masing indikator sebesar $80 \%$ pada aspek sikap belajar, $74 \%$ pada aspek sosial-emosional, $81 \%$ pada aspek teknis, $78 \%$ pada aspek kognitif. Persentase tingkat literasi digital siswa dapat dilihat pada Tabel 1.

Tabel 1. Aspek dan kategori tingkat kemampuan literasi digital

\begin{tabular}{|c|c|c|c|c|}
\hline No & Aspek & Deskripsi & Skor & KG \\
\hline 1 & Sikap Belajar & $\begin{array}{l}\text { Sudut pandang individu terhadap media SGF, } \\
\text { apakah dianggap mendukung atau justru } \\
\text { mengahambat belajar siswa }\end{array}$ & $80 \%$ & $\mathrm{~T}$ \\
\hline 2 & Sosial Emosional & Berkolaborasi dalam melakukan tugas & $74 \%$ & $\mathrm{~S}$ \\
\hline 3 & Teknis & $\begin{array}{l}\text { Memiliki keterampilan operasional dalam } \\
\text { menggunakan media pembelajaran berbasis ICT } \\
\text { yaitu SGF }\end{array}$ & $81 \%$ & $\mathrm{~T}$ \\
\hline 4 & Kognitif & Kemampuan berpikir kritis & $78 \%$ & $\mathrm{~T}$ \\
\hline & & Rerata & $78 \%$ & $\mathrm{~T}$ \\
\hline
\end{tabular}


Secara umum tingkat literasi digital siswa sudah bagus, hal ini terlihat pada Tabel 1. Pada aspek sosialemosional masuk kategori sedang, ditemukan bahwa subjek penelitian sering menggunakan aplikasi WhatsApp untuk bertanya tentang tugas sekolah dengan temannya. Hal ini mempengaruhi proses transformasi dari pendidikan konvensional ke teknologi digital.

Berikut kutipan wawancara secara mendalam terhadap subjek penelitian.

$\mathrm{P}$ : "Apakah anda menggunakan media digital dalam bertukar pikiran dengan teman mengenai materi bangun ruang sisi lengkung ?"

S1 : "Ya, saya menggunakan media digital untuk bertukar pikiran karena lebih mudah dan menyenangkan, media SGF memudahkan saya belajar bersama teman jika tidak mengerti dapat bertukar pendapat"

S1 menambahkan bahwa materi bangun ruang sisi lengkung mudah dipahami jika menggunakan ilustrasi seperti video yang ada dalam media SGF.

S2 dan S3 menyatakan hal yang serupa akan tetapi keduanya berpendapat bahwa guru sebaiknya sering menggunakan media digital saat pembelajaran di kelas bukan hanya sekali atau dua kali.

Hal ini terjadi karena tidak semua siswa dapat bersosialisasi dan berkolaborasi dalam melakukan tugas, siswa masih membutuhkan penyesuaian dalam menggunakan media SGF, hal ini sesuai dengan hasil penelitian Setyaningsih \& Prihantoro (2019) yang menyatakan bahwa penggunaan dan pemanfaatan e-learning dalam proses pembelajaran belum berkembang, sehingga diperlukan proses adaptasi saat menggunakan e-learning. Penggunaan media digital saat pembelajaran sangat bermanfaat selain dapat membantu memahami materi pelajaran juga dapat membuat suasana pembelajaran lebih menyenangkan (Kusumaningrum, Verdianingsih, \& Umardiyah, 2019; Lestari et al., 2017).

Persentase rata-rata tertinggi terdapat pada aspek teknis sebanyak 81\%. Diketahui bahwa media SGF dapat digunakan dan dimanfaatkan oleh siswa pada pembelajaran. Bentuk pemanfaatan mediapun bermacammacam, seperti media digital untuk mencari informasi melalui internet.

Adapun kutipan wawancara terkait aspek teknis tingkat kemampuan literasi digital sebagai berikut.

P : "Apakah anda dapat mengoperasikan media SGF (Space Geometry Flipbook) dengan baik ?"

S1 : "Ya, saya dengan mudah dapat mengoperasikannya, karena saya sudah terbiasa membaca buku digital di internet ketika belajar sendiri dirumah"

S2 : "Tombol-tombol dan tulisan pada media SGF seperti tombol play pada video telah memberikan saya petunjuk bahwa video tersebut dapat di jalankan jika tombol play di tekan. Sehingga dengan mudah saya mengaplikasikannya berdasarkan petunjuk yang ada"

S3 : "ya, saya dapat mengoperasikannya. Sebelumnya saya belum paham cara menggunakannya tetapi ketika saya melihat tulisan petunjuk saya mencoba untuk menekan tombol pada tulisan tersebut. Kemudian muncul petunjuk penggunaan media SGF sehingga saya paham cara menggunakannya" 
DOI: https://doi.org/10.24127/ajpm.v10i3.3898

Maka dapat disimpulkan bahwa siswa dapat menggunakan media SGF melalui petunjuk penggunaan yang terdapat dalam media meskipun sebagian kecil siswa melewati konten petunjuk. Hal ini menunjukan bahwa keterampilan operasional dalam penggunaan media digital untuk belajar dan berdiskusi dimilki oleh siswa. Hal ini sesuai dengan hasil penelitian Komariah, Suhendri, \& Hakim (2018) yang menyatakan bahwa tampilan info dalam media pembelajaran dapat mempermudah siswa dalam mengoperasikan media pembelajaran.

Pada aspek sikap belajar mendapat persentase $80 \%$ masuk kategori tinggi. Ditemukan bahwa subjek penelitian merasa bahwa belajar dengan media SGF lebih baik karena membuat kegiatan belajar menjadi lebih menarik selain dapat meningkatkan motivasi belajar juga menjadikan pelajar independen.

Adapun kutipan wawancara terkait sikap belajar diantaranya yaitu:

$\mathrm{P} \quad$ : "Apakah anda merasa lebih baik menggunakan media digital ketika belajar?"

S1 : "Tampilan media SGF sangat menarik sehingga saya lebih semangat dalam belajar materi bangun ruang. media SGF dapat digunakan saat belajar mandiri di rumah dan dapat dilakukan berulang-ulang sampai paham"

S2 : Tentu, karena dengan meggunakan media digital belajar menjadi lebih menarik, yang biasanya mengantuk jadi tidak mengantuk. Karena ketika saya baca buku sering mengantuk. Sedangkan media SGF memuat gambar dan video yang menarik"

S3 : "Ya, belajar menggunakan media digital lebih menarik perhatian , karena dalam media terdapat video penjelasan serta ilustrasi. Dengan adanya animasi dan video tersebut memudahkan saya memahami pelajaran serta tidak mudah bosan saat kegiatan pembelajaran"

Dapat disimpulkan bahwa siswa merasa lebih baik menggunakan media digital ketika belajar karena media SGF dapat mendukung belajar siswa. Hal ini serupa dengan pendapat Swara, Ambiyar, Fadhilah, \& Syahril (2020) yang menyatakan bahwa penggunaan multimedia dalam pembelajaran matematika dapat menunjang kegiatan pembelajaran blended learning agar pembelajaran online lebih efektif dan menginterasikan guru dengan siswa. Hamzah (2015) juga menjelaskan bahwa media digital menjadi alat pelengkap sistem pendidikan tradisional serta mendukung pembelajaran kolaboratif dan kooperatif peserta didik.

Aspek kognitif yang dimaksud dalam penelitian ini adalah kemampuan siswa dalam menemukan informasi dan memahaminya dengan persentase $78 \%$ masuk kategori tinggi. Ditemukan bahwa subjek penelitian memiliki kemampuan untuk menganalisis dan mengevaluasi konten media, khusunya media digital meskipun belum menyeluruh.

Adapun kutipan wawancara terkait aspek kognitif sebagai berikut.

P : "Apakah media SGF membantu anda memahami unsur-unsur bangun ruang dan dapat menyelesaikan soal dalam media SGF ?"

S1 : "Ya, saya dapat memahami unsur-unsur bangun ruang dengan menonton video penjelasan dalam media SGF serta dapat menyelesaikan contoh soalnya. Penjelasan 
DOI: $\underline{\text { https://doi.org/10.24127/ajpm.v10i3.3898 }}$

dalam video sudah runtut dan mudah dipahami"

S2 : "Saya sudah menonton video penjelasan tersebut dan sangat mudah dipahami tetapi ketika menyelesaikan contoh soal saya sedikit bingung karena dalam video dan soal sedikit berbeda"

S3 : "Video menjelaskan tentang asal usul rumus sehingga memudahkan saya mengingat serta memahami unsur-unsur bangun ruang dan penggunaan rumus. Akan tetapi contoh soal kurang banyak sehingga ketika diberikan soal ada yang kurang dipahami"

Hal ini terjadi karena sedikitnya pembelajaran dan penugasan pada pembelajaran matematika yang melibatkan media digital untuk meningkatkan kreativitas literasi digital siswa. Sehingga guru harus sering menggunakan media digital saat pembelajaran seperti media SGF agar perkembangan kognitif siswa lebih baik. Dapat disimpulkan bahwa penggunaan media SGF dapat merangsang perkembangan kognitif siswa dalam belajar. Hal ini relevan dengan penelitian Febriyanti \& Irawan (2017) yang menyatakan bahwa penggunaan $e$ book atau buku digital dapat meningkatkan minat dan hasil belajar kognitif siswa. Selain itu, penelitian ini sama dengan hasil penelitian Amalia \& Kustijono (2017) yang menjelaskan bahwa penggunaan $e$-book sigil efektif melatih keterampilan berpikir kritis dan meningkatkan minat baca yang berarti jika minat baca meningkat maka kualitas pendidikan menjadi lebih baik.

\section{KESIMPULAN DAN SARAN}

Berdasarkan hasil analisis yang telah dilakukan diperoleh tingkat literasi digital siswa dengan berbantuan media Space Geometry Flipbook (SGF) dari masing-masing indikator yaitu, pada aspek sikap belajar masuk kategori tinggi yang berarti bahwa siswa merasa lebih baik menggunakan media digital ketika belajar karena media SGF dapat mendukung belajar siswa. Sedangkan pada aspek sosial-emosional masuk kategori sedang yang berarti bahwa tidak semua siswa dapat bersosialisasi dan berkolaborasi dalam melakukan tugas serta siswa masih membutuhkan penyesuaian dalam penggunaan media pembelajaran. Pada aspek teknis masuk kategori tinggi yang berarti keterampilan operasional dalam penggunaan media digital untuk belajar dan berdiskusi dimilki oleh siswa. Pada aspek kognitif masuk kategori tinggi yang berarti penggunaan media SGF dalam pembelajaran secara berkelanjutan dapat mendorong kreativitas literasi digital siswa.

\section{DAFTAR PUSTAKA}

A'yuni, Q. Q. (2015). Literasi Digital Remaja Di Kota Surabaya. Jurnal Fakultas Ilmu Sosial Dan Ilmu Politik Universitas Airlangga Surabaya, 4(2), 1-15. Retrieved from

http://journal.unair.ac.id/literasidigital-remaja-di-kota-surabayaarticle-9195-media-136-category8.html

Amalia, F., \& Kustijono, R. (2017). Efektifitas Penggunaan E-Book dengan Sigil untuk Melatihkan Kemampuan Berpikir Kritis. Prosiding Seminar Nasional Fisika (SNF), 1(November), 81-85.

Andini, S., Fitriana, L., \& Budiyono, B. (2018). Geometry in flipbook multimedia, a role of technology to improve mathematics learning quality: The case in madiun, east Java. Journal of Physics: 
DOI: $\underline{\text { https://doi.org/10.24127/ajpm.v10i3.3898 }}$

Conference Series, 1008(1). https://doi.org/10.1088/17426596/1008/1/012077

Anggraeni, H., Fauziyah, Y., \& Fahyuni, E. F. (2019). Penguatan Blended Learning Berbasis Literasi Digital Dalam Menghadapi Era Revolusi Industri 4.0. Al-Idarah: Jurnal Kependidikan Islam, 9(2), 190-203. Retrieved from http://ejournal.radenintan.ac.id/inde x.php/idarohe-ISSN:2580-

2453https://doi.org/10.24042/alidar ah.v9i2.5168

Casey, L., \& Hallissy, M. (2016). Live Learning: Online Teaching, Digital Literacy and the Practice of Inquiry. Irish Journal of Technology Enhanced Learning, l(1), $1-7$. https://doi.org/10.22554/ijtel.v1i1.4

Febriyanti, C., \& Irawan, A. (2017). Meningkatkan Kemampuan Pemecahan Masalah dengan Pembelajaran Matematika Realistik. Delta-Pi: Jurnal Matematika Dan Pendidikan Matematika, 6(1), 31-41. Retrieved from http://ejournal.unkhair.ac.id/index.p $\mathrm{hp} /$ deltapi/article/view/350

Fernandes, R. (2019). Relevansi Kurikulum 2013 dengan Kebutuhan Peserta Didik di Era Revolusi 4.0. Journal of Sociology Research and Education, 6(2), 70-80.

Hamzah, R. E. (2015). Penggunaan Media Sosial di Kampus Dalam Mendukung Pembelajaran Pendidikan. Jurnal Wacana, $X I V(1), \quad 45-70$. Retrieved from http://journal.moestopo.ac.id/index. php/wacana/article/view/89

Hardiansyah, D. (2016). Pengembangan Media Flash Flipbook dalam Pembelajaran Perakitan Komputer untuk Meningkatkan Hasil Belajar Siswa Kelas X TKJ SMK Negeri 7 Surabaya. It-Edu, 1(02), 5-11.

Haryanti, F., \& Saputro, B. A. (2016).
Pengembangan Modul Matematika Berbasis Discovery Learning Berbantuan Flipbook Maker Untuk Meningkatkan Kemampuan Pemahaman Konsep Siswa Pada Materi Segitiga. KALAMATIKA Jurnal Pendidikan Matematika, $1(2), \quad 147$. https://doi.org/10.22236/kalamatika .vol1 no2.2016pp147-161

Hasanah, S. N., Effendi, M. M., \& Putri, O. R. U. (2020). Pengembangan Space Geometry Flipbook Audio Visual Berbasis Literacy Digital Untuk Siswa Smp. AKSIOMA: Jurnal Program Studi Pendidikan Matematika, 9(3), 506. https://doi.org/10.24127/ajpm.v9i3. 2951

Indariani, A., Ayni, N., Pramuditya, S. A., \& Noto, M. S. (2019). Teknologi Buku Digital Matematika dan Penerapan Potensialnya dalam Distance Learning. JNPM (Jurnal Nasional Pendidikan Matematika), 3(1),

1. https://doi.org/10.33603/jnpm.v3i1. 1870

Komariah, S., Suhendri, H., \& Hakim, A. R. (2018). Pengembangan Media Pembelajaran Matematika Siswa SMP Berbasis Android. JKPM (Jurnal Kajian Pendidikan Matematika), 4(1), 43. https://doi.org/10.30998/jkpm.v4i1. 2805

Kurniawati, J., \& Baroroh, S. (2016). Literasi Media Digital Mahasiswa Universitas Muhammadiyah Bengkulu. Jurnal Komunikator, 8(2), 52-66.

Kusumaningrum, A. D., Verdianingsih, E., \& Umardiyah, F. (2019). Pengembangan Lembar Kerja Siswa (LKS) Berbasis E- book Pada Materi Himpunan untuk Siswa Kelas VII MTs/SMP. Journal of Educatio $n$ and Management Studies and Management Studies, 2(5), 35-44. 
Lestari, E., Sunardi, \& Suryani, N. (2017). Jurnal Penelitian Teknologi Pendidikan http://jurnal.fkip.uns.ac.id/teknodik a. Teknodika, Jurnal Penelitian Teknologi Pendidikan, 15(01), 1625.

OECD. (2015). Programme for International Student Assessment Result for PISA 2015. Oecd, 1-8. Retrieved from https://www.oecd.org/pisa/PISA2015-Indonesia.pdf

Rahayu, T., \& Mayasari, T. (2018). Profil kemampuan awal literasi digital dalam pembelajaran fisika siswa SMK Kota Madiun. Seminar Nasional Quantum, 25, 431-437. Retrieved from http://seminar.uad.ac.id/index.php/q uantum/article/download/294/244

Rahmawaty, M. E., \& Karwanto. (2021). Strategi Kepala Sekolah dalam Upaya Memotivasi Minat Membaca Buku Digital Siswa. Inspirasi Manajemen Pendidikan, 09(01), 13-23.

Raihanah, A., Putri, O. R. U., \& Effendi, M. M. (2020). Literasi Digital dan Pemahaman Konsep Himpunan Siswa SMP Menggunakan Media Pembelajaran GUI Matlab. Jurnal Elemen, 6(1), 13-24. https://doi.org/10.29408/jel.v6i1.13 09

Reflianto, \& Syamsuar. (2018). Pendidikan dan Tantangan Pembelajaran Berbasis Teknologi Informasi di Era Revolusi Industri 4.0. Jurnal Ilmiah Teknologi Pendidikan, 6(2), 1-13.

Rusli, M., \& Antonius, L. (2019). Meningkatkan Kognitif Siswa SMAN I Jambi Melalui Modul Berbasis E-Book Kvisoft Flipbook Maker. Jurnal Sistem Komputer Dan Informatika (JSON), 1(1), 59. https://doi.org/10.30865/json.v1i1.1 397
Sari, W. K., \& Nada, E. I. (2020). Analisis Literasi Digital Calon Guru Kimia Dalam Pelaksanaan Ppl Berbasis Virtual Di Masa Pandemi Covid-19. Orbital: Jurnal Pendidikan Kimia, 4(2), 111-121. https://doi.org/10.19109/ojpk.v4i2. 6704

Selvia, Suratman, D., \& Hartoyo, A. (2016). Pengembangan Media Pembelajaran Matematika Menggunakan Flipbook Dikaitkan Dengan Kemampuan Komunikasi Matematis Siswa SMA. Jurnal Pendidikan Dan Pembelajaran Khatulistiwa, 7(1).

Setyaningsih, R., \& Prihantoro, E. (2019). Model Penguatan Literasi Digital Melalui Pemanfaatan e-Learning. ASPIKOM, 3, 1200-1214.

Swara, G. Y., Ambiyar, A., Fadhilah, F., \& Syahril, S. (2020). Pengembangan multimedia pembelajaran matematika sebagai upaya mendukung proses pembelajaran blended learning. 7(2), 105-117.

Uswatun Khasanah, \& Herina. (2019). Membangun Karakter Siswa Melalui Literasi Digital Dalam Menghadapi Pendidikan Abad 21 (Revolusi Industri 4.0). Prosiding Seminar Nasional Pendidikan Program Pascasarjana Universitas Pgri Palembang, 21, 999-1015.

Utami, F. M. (2020). Pentingnya Pendidikan Karakter Dalam Literasi Digital Matematika. Seminarmat.Ump.Ac.Id, (20), 2011-2019. Retrieved from https://seminarmat.ump.ac.id/index. php/semadik/article/view/291

Willy Arif Indhaka, Eko Supraptono, N. S. (2016). Penerapan Buku Sekolah Elektronik Berbasis Android Dalam Materi Ajar Besaran Dan Satuan. Didaktikum: Jurnal Penelitian Tindakan Kelas, 17(2), 1-8. 